\title{
Epidural Fentanyl and Fentanyl Plus Magnesium for Post-Operative Analgesia in Lower Extremity Surgery
}

\author{
Ajay Babu Ramakrishnan ${ }^{\oplus 1}$, S. Ankalagowri Sankardevar ${ }^{2}$, Nischala Reddy G ${ }^{\circledR 3}$, Uthkala B Hegde ${ }^{\odot 4}$ \\ ${ }^{1}$ Assistant Professor, Department of Anesthesia, Madha Medical College and Hospital, Chennai, Tamilnadu, India, ${ }^{2}$ Dr. Sheshaiah's Prajavaidyashala Hospital, Guntur, \\ Andhra Pradesh, India, ${ }^{3}$ Registrar, Department of Anesthesia, Virinchi Hospital, Hyderabad, Telangana, India, ${ }^{4}$ Professor, Department of Anaesthesiology, MVJ Medical \\ College and Research Hospital, Hoskote, Banglore, India.
}

\section{Abstract}

Background: The present study was conducted to assess the efficacy of epidural fentanyl with a combination of epidural fentanyl and magnesium in lower extremity surgery. Subjects and Methods : This study was conducted on 100 ASA I/II patients scheduled to undergo elective lower limb orthopedic surgeries. Group I patients received epidural fentanyl $50 \mu \mathrm{g}$ (1 cc) diluted and made up to 6cc with normal saline. Group II patients received epidural fentanyl $50 \mu \mathrm{g}(1 \mathrm{cc})+$ Magnesium sulphate $50 \mathrm{mg}$ (4 units in insulin syringe of 50\% solution) diluted and made up to $6 \mathrm{cc}$ with normal saline. Patient data such as indication for surgery, the anesthetic details, intraoperative monitoring, post-operative follow-up, etc was recorded. Results: Each group had 36 males and 14 females. Time is taken for the highest sensory level in group I was $13.92 \pm 4.50$ minutes and $12.24 \pm 3.43$ minutes in groups I and II respectively. The mean duration of surgery was $99.00 \pm 13.31$ minutes in group I and $92.20 \pm 15.21$ in group II. Time for Regression to L1 was $118.80 \pm 13.41$ and $119.60 \pm 17.85$ minutes in group I and II respectively. The duration of analgesia (min) was $107.00 \pm 25.82$ and $143.40 \pm 39.57$ minutes in group I and II respectively. Common adverse events were nausea/ vomiting seen 2 in group I and 4 in group II and urinary retention seen 0 in group I and 2 in group II. The difference was non- significant (P $>0.05)$. Conclusion: Authors found that the addition of magnesium sulfate to epidural fentanyl for elective lower limb orthopedic surgeries has prolonged the duration of fentanyl analgesia without any significant side effects.

Keywords: Epidural fentanyl, magnesium sulfate, orthopedic surgeries

Corresponding Author: Uthkala B Hegde, Professor, Department of Anaesthesiology, MVJ Medical College and Research Hospital, Hoskote, Banglore, India.

E-mail: ubshetty8@gmail.com

Received: 29 July 2020

Revised: 30 August 2020

Accepted: 08 September 2020

Published: 16 December 2020

\section{Introduction}

Acute pain has been defined as the normal, predicted, physiological response to an adverse chemical, thermal, or mechanical stimulus. ${ }^{[1]}$ Continuous spinal epidural (CSE) block combines the rapidity, density, and reliability of the subarachnoid block with the flexibility of continuous epidural block to extend the duration of analgesia. ${ }^{[2]}$ The CSE technique is used routinely for major orthopedic surgery and obstetrics. The role of epidural anesthesia and analgesia in reducing the incidence and severity of perioperative physiologic derangements, in addition to relieving pain has been reported in several studies. ${ }^{[3]}$

Drugs used for epidural analgesia are local anesthetics, opioids, local anesthetic- opioid combinations and other adjuvants. A variety of adjuvants are used for epidural infusion to enhance analgesia while minimizing side effects, like
Clonidine, epinephrine, magnesium etc. ${ }^{[4]}$ These adjuvants have been added to opioids epidurally to prolong analgesia and reduce the adverse effects observed when opioids are used alone. Owing to its high lipid solubility, fentanyl offers some advantages for epidural analgesia. ${ }^{[5]}$ Owing to the rapid onset and short duration of action of fentanyl, it is the drug of choice for postoperative acute pain. N-methyl-d-aspartate (NMDA) receptors located in the dorsal horn of the spinal cord have a role in the modulation of central sensitization of noxious stimulus. Magnesium, through a non-competitive mechanism, blocks the NMDA receptors and results in natural calcium antagonism and when administered epidurally is proved to prolong the duration of spinal opioid analgesia. ${ }^{[6]}$ The present study was conducted to compare and study the efficacy of epidural fentanyl with a combination of epidural fentanyl and magnesium administered postoperatively for lower extremity surgery. 


\section{Subjects and Methods}

This study was conducted in the Department of Anesthesia. It comprised of 100 ASA I/II patients scheduled to undergo elective lower limb orthopedic surgeries. Ethical clearance was obtained from the PESIMSR Institutional Ethics committee, PESIMSR, Kuppam. All patients were informed regarding the study and their consent was obtained.

Patients have divided into two groups. Group I patients received epidural fentanyl $50 \mu \mathrm{g}$ (1cc) diluted and made up to $6 \mathrm{cc}$ with normal saline. Group II patients received epidural fentanyl $50 \mu \mathrm{g}(1 \mathrm{cc})+$ Magnesium sulphate $50 \mathrm{mg}$ (4 units in insulin syringe of $50 \%$ solution) diluted and made up to $6 \mathrm{cc}$ with normal saline.

Patient data such as indication for surgery, the anesthetic details, intraoperative monitoring, post-operative follow-up, etc was recorded. Routine intra-operative monitoring of pulse rate, blood pressure, oxygen saturation and respiratory rate was done for all the patients and the following parameters were noted such as time taken for highest sensory level, time for regression to L1, duration of surgery and duration of analgesia. Results obtained were recorded and analyzed statistically.

\section{Results}

[Table 1] shows the distribution of patients. Each group had 36 males and 14 females.

[Table 2, Figure 1] shows that the time is taken for the highest sensory level in group I was $13.92 \pm 4.50$ minutes and $12.24 \pm 3.43$ minutes in group I and II respectively. The mean duration of surgery was $99.00 \pm 13.31$ minutes in group I and $92.20 \pm 15.21$ in group II. Time for regression to L1 was $118.80 \pm 13.41$ and $119.60 \pm 17.85$ minutes in group I and II respectively. The duration of analgesia (min) was $107.00 \pm 25.82$ and $143.40 \pm 39.57$ minutes in group I and II respectively.

[Figure 2] shows that common adverse events were nausea/ vomiting seen 2 in group I and 4 in group II and urinary retention seen 0 in group I and 2 in group II. The difference was non- significant $(\mathrm{P}>0.05)$.

\section{Discussion}

The use of epidural analgesia for pain relief was improved by the use of epidural opioids after the discovery of opioid receptors in the dorsal horn of the spinal cord. ${ }^{[7]}$ Fentanyl is a suitable opioid for infusion into the epidural space. ${ }^{[8]}$ The advantages of fentanyl over other opioids are that it easily crosses the lumbar dura and quickly penetrates the lipid phase of the underlying tissue of the cord. Various adjuvants have been added to opioids epidurally

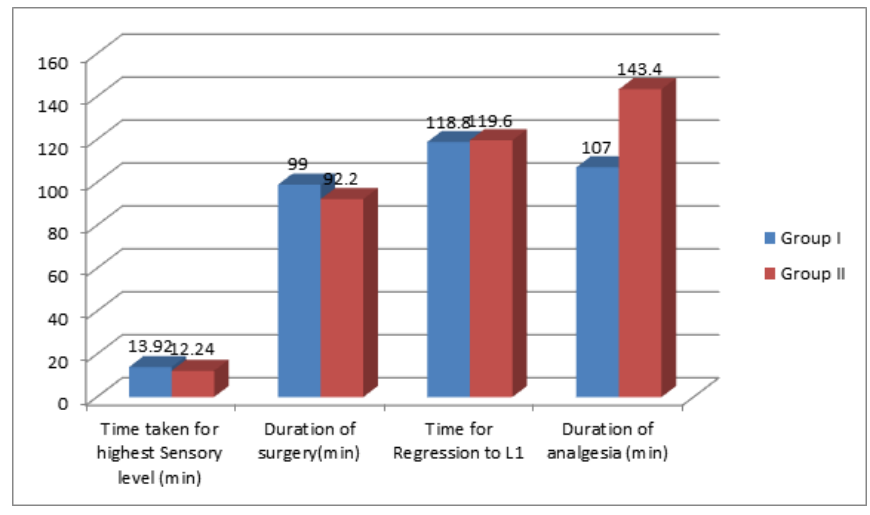

Figure 1: Comparison of parameters

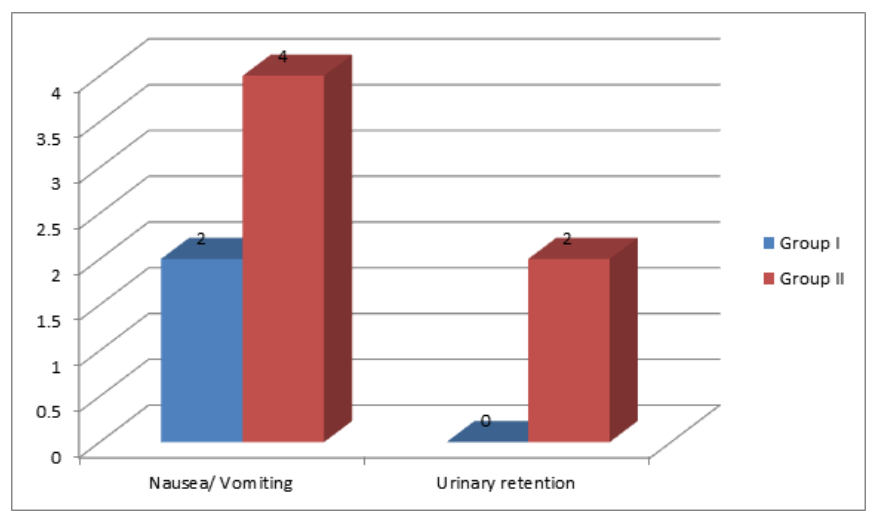

Figure 2: Adverse events in both groups

to prolong analgesia and reduce the side effects observed when opioids are used alone.Magnesium, which is the fourth most plentiful cation in the body, is proved to have antinociceptive effects in animal and human models of pain. ${ }^{[9]}$ This effect is based on the regulation of calcium influx into the cell that is natural physiological calcium antagonism and antagonism of NMDA receptors. Coadministration of epidural magnesium for postoperative epidural analgesia has provided a pronounced reduction in patient-controlled fentanyl consumption without any side effects. ${ }^{[10]}$ The present study was conducted to assess the efficacy of epidural fentanyl with a combination of epidural fentanyl and magnesium administered postoperatively for lower extremity surgery.

In the present study, patients were divided into 2 groups. Group I patients received epidural fentanyl with normal saline and group II patients received epidural fentanyl and magnesium sulphate with normal saline. Ghoneem et al, ${ }^{[11]}$ evaluated the analgesic efficacy of single bolus administration of epidural fentanyl, magnesium sulfate, and a combination of both in patients undergoing hip surgeries under spinal anesthesia. 
Table 1: Distribution of patients

\begin{tabular}{lll}
\hline Groups & Group I & Group II \\
\hline Agent & Epidural fentanyl with normal saline & $\begin{array}{l}\text { Epidural fentanyl and magnesium sul- } \\
\text { phate }\end{array}$ \\
\hline Male & 36 & 36 \\
Female & 14 & 14 \\
\hline
\end{tabular}

Table 2: Comparison of parameters

\begin{tabular}{llll}
\hline Groups & Group I & Group II & P-value \\
Time taken for highest Sensory level (min) & $13.92 \pm 4.50$ & $12.24 \pm 3.43$ & 0.12 \\
Duration of surgery(min) & $99.00 \pm 13.31$ & $92.20 \pm 15.21$ & 0.05 \\
Time for Regression to L1 & $118.80 \pm 13.41$ & $119.60 \pm 17.85$ & 0.89 \\
Duration of analgesia (min) & $107.00 \pm 25.82$ & $143.40 \pm 39.57$ & 0.01 \\
\hline
\end{tabular}

Ninety patients age ranged 20-65 years, American Society of Anesthesiology I-III, undergoing elective hip surgery under spinal anesthesia were investigated. After wearing off of spinal anesthesia, the patients were allocated into three groups to receive a single bolus epidural injection of fentanyl $1 \mu \mathrm{g} / \mathrm{kg}$ in the fentanyl (F) group, magnesium sulfate $75 \mathrm{mg}$ in the magnesium sulfate $(\mathrm{M})$ group, and a combination of both in the fentanyl magnesium sulfate (FM) group. All were diluted to a total volume of $10 \mathrm{ml}$. Visual analog scale, duration of analgesia, and total consumption of rescue analgesia were recorded.A combination of epidural fentanyl $(1 \mu \mathrm{g} / \mathrm{kg})$ and magnesium sulfate $(75 \mathrm{mg})$ produced a significant reduction of postoperative visual analog scale at 3 and $6 \mathrm{~h}$ with a longer duration of analgesia and a lower rescue analgesic consumption without increased side effects.

In this study time taken for the highest sensory level in group I was $13.92 \pm 4.50$ minutes and $12.24 \pm 3.43$ minutes in group I and II respectively. The mean duration of surgery was $99.00 \pm 13.31$ minutes in group I and $92.20 \pm 15.21$ in group II. Time for Regression to L1 was $118.80 \pm 13.41$ and $119.60 \pm 17.85$ minutes in group I and II respectively. The duration of analgesia (min) was $107.00 \pm 25.82$ and $143.40 \pm 39.57$ minutes in group I and II respectively.

Bilir et al, ${ }^{[12]}$ used fentanyl PCEA in Group F and fentanyl PCEA with $50 \mathrm{mg}$ bolus $\mathrm{Mg}$ and continuous $\mathrm{Mg}$ infusion epidurally in Group FM, time to first analgesic requirement (comparable to the duration of analgesia in our study) was slightly longer in Group FM (51.6 min) compared to Group F (37.1 min). Compared with patients in Group F, patients in Group FM received smaller doses of epidurally infused fentanyl at all time points after $30 \mathrm{~min}$. There was a $25 \%$ reduction in fentanyl consumption in Group FM at the end of $24 \mathrm{hr}$ compared to Group F. Thus, the addition of Mg allowed lesser requirement of fentanyl in the postoperative period due to its NMDA receptor antagonist action and potentiation of opioid analgesic effects. This is comparable to the results of the present study wherein adding $\mathrm{Mg}(50 \mathrm{mg})$ to fentanyl (50 $\mu \mathrm{g}$ ) epidurally as a single dose markedly increased the duration of fentanyl analgesia in group FM compared to group F.

We found that common adverse events were nausea/vomiting seen 2 in group I and 4 in group II and urinary retention seen 0 in group I and 2 in group II. The limitation of the study is the small sample size.

\section{Conclusion}

The authors found that the addition of magnesium sulfate to epidural fentanyl for elective lower limb orthopedic surgeries has prolonged the duration of fentanyl analgesia without any significant side effects.

\section{References}

1. Curatolo M, Schnider TW, Petersen-Felix S, Weiss S, Signer C, Scaramozzino P, et al. A Direct Search Procedure to Optimize Combinations of Epidural Bupivacaine, Fentanyl, and Clonidine for Postoperative Analgesia. Anesthesiol. 2000;92(2):325-325. Available from: https://dx.doi.org/10. 1097/00000542-200002000-00012.

2. Paech MJ, Pavy TJ, Orlikowski CE. Postoperative epidural infusion: A randomized, double-blind, dose-finding trial of clonidine in combination with bupivacaine and fentanyl. Anesth Analg. 1997;84:1323-1323. Available from: https: //doi.org/10.1097/00000539-199706000-00027.

3. Niemi G, Breivik H. Adrenaline markedly improves thoracic epidural analgesia produced by a low-dose infusion of bupivacaine, fentanyl and adrenaline after major surgery: A randomised, double-blind, cross-over study with and without adrenaline. Acta Anaesthesiol Scand. 1998;42(8):897-909. Available from: https://dx.doi.org/10.1111/j.1399-6576.1998. tb05348.x. 
4. Lauretti GR, Gomes JMA, Reis MP, Pereira NL. Low doses of epidural ketamine or neostigmine, but not midazolam, improve morphine analgesia in epidural terminal cancer pain therapy. J Clin Anesth. 1999;11(8):663-668. Available from: https: //dx.doi.org/10.1016/s0952-8180(99)00122-1.

5. Nickells JS, Vaughan DJA, Lillywhite NK, Loughnan B, Hasan M, Robinson PN. Speed of onset of regional analgesia in labour: a comparison of the epidural and spinal routes. Anaesthesia. 2000;55(1):17-20. Available from: https://dx.doi.org/10.1046/ j.1365-2044.2000.01071.x.

6. Arcioni R, Palmisani S, Tigano S, Santorsola C, Sauli V, Romanò $\mathrm{S}$, et al. Combined intrathecal and epidural magnesium sulfate supplementation of spinal anesthesia to reduce postoperative analgesic requirements: a prospective, randomized, double-blind, controlled trial in patients undergoing major orthopedic surgery. Acta Anaesthesiol Scand. 2007;51(4):482489. Available from: https://dx.doi.org/10.1111/j.1399-6576. 2007.01263.x.

7. Robert JM, Kroin W, Leong P, Perry, Kenneth JT. Intrathecal Magnesium Prolongs Fentanyl Analgesia: A Prospective, Randomized, Controlled Trail. Br J Anaesth. 2007;98(4):519542.

8. Ranasinghe JS, Steadman J, Toyama T, Lai M. Combined spinal epidural anaesthesia is better than spinal or epidural alone for Caesarean delivery. Br J Anaesth . 2003;91(2):299-300. Available from: https://doi.org/10.1093/bja/aeg596.

9. Lytle SA, Goldsmith DM, Neuendorf TL, Lowry ME. Postoperative analgesia with epidural fentanyl. J Am Osteopath Assoc. 1991;91(6):547-547.
10. Salomäki TE, Laitinen JO, Nuutinen LS. A Randomized Double-blind Comparison of Epidural versus Intravenous Fentanyl Infusion for Analgesia after Thoracotomy. Anesthesiology. 1991;75(5):790-795. Available from: https://dx.doi.org/ 10.1097/00000542-199111000-00010.

11. Ghoneem HA, El-Harty MA, El-Daba AA, Mostafa SF. A comparative study between epidural fentanyl, magnesium sulfate, or both for postoperative analgesia in hip surgeries. Tanta Med J. 2018;46(4):275-80.

12. Bilir A, Gulec S, Erkan A, Ozcelik A. Epidural magnesium reduces postoperative analgesic requirement. $\mathrm{Br} \mathrm{J}$ Anaesth. 2007;98(4):519-523. Available from: https://dx.doi.org/10. 1093/bja/aem029.

Copyright: (C) the author(s), 2020. It is an open-access article distributed under the terms of the Creative Commons Attribution License (CC BY 4.0), which permits authors to retain ownership of the copyright for their content, and allow anyone to download, reuse, reprint, modify, distribute and/or copy the content as long as the original authors and source are cited.

How to cite this article: Ramakrishnan $\mathrm{AB}$, Sankardevar SA, Reddy G N, Hegde UB. Epidural Fentanyl and Fentanyl Plus Magnesium for Post-Operative Analgesia in Lower Extremity Surgery. Acad. Anesthesiol. Int. 2020;5(2):35-38.

DOI: dx.doi.org/10.21276/aan.2020.5.2.7

Source of Support: Nil, Conflict of Interest: None declared. 